\title{
Wnt Signaling in Amygdala-Dependent Learning and Memory
}

\author{
Kimberly A. Maguschak ${ }^{1,2}$ and Kerry J. Ressler ${ }^{1,3}$ \\ ${ }^{1}$ Department of Psychiatry and Behavioral Sciences, Yerkes National Primate Research Center, Emory University, Atlanta, Georgia 30329, ${ }^{2}$ Department of \\ Brain and Cognitive Sciences, Massachusetts Institute of Technology, Cambridge, Massachusetts 02139, and ${ }^{3}$ Howard Hughes Medical Institute, Emory \\ University, Atlanta, Georgia 30329
}

In addition to its role in cellular development and proliferation, there are emerging in vitro data implicating the Wnt/ $\beta$-catenin pathway in synaptic plasticity. Yet in vivo studies have not examined whether Wnt activity is required for learning and memory. In the amygdala during fear memory formation, we found that many Wnt-signaling genes were dynamically regulated, with an immediate decrease, followed by an eventual normalization during memory consolidation. This rapid decrease in Wnt mRNA was confirmed with individual quantitative PCR and in situ hybridization. We then manipulated Wnt signaling with a specific peptide antagonist (Dkk-1) or agonist (Wnt1) injected stereotaxically into the adult amygdala during fear learning. We found that neither manipulation had an effect on locomotion, anxiety, fear acquisition, or fear expression. However, both Wnt modulators prevented long-term fear memory consolidation without affecting short-term memory. Dkk-1 and Wnt infusions had destabilizing, but opposite, effects on the requisite $\beta$-catenin/ cadherin dynamic interactions that occur during consolidation. These data suggest that dynamic modulation of Wnt/ $\beta$-catenin signaling during consolidation is critical for the structural basis of long-term memory formation.

\section{Introduction}

Wnt/ $\beta$-catenin signaling is important for a variety of cellular processes including development, cell proliferation, cell fate, and motility (Moon et al., 2004; Lee et al., 2008). Wnt proteins constitute a large family of secreted molecules that can bind to several distinct receptors, activating different signaling pathways, including the $\beta$-catenin pathway. When Wnts bind to a member of the Frizzled family of cell surface receptors, the transmembrane lipoprotein receptor-related proteins 5 and 6 (LRP5/6) are recruited, and the cytoplasmic protein Dishevelled (Dvl) is activated (Bhanot et al., 1996). Dvl activation leads to the inhibition of glycogen synthase kinase-3 (GSK3), which phosphorylates $\beta$-catenin, resulting in its degradation. The inhibition of $\beta$-catenin degradation increases its stability, resulting in nuclear translocation. In the nucleus, it binds to the T-cell factor/lymphoid enhancer factor (TCF/LEF) family of transcription factors, which regulate the expression of Wnt target genes (Logan and Nusse, 2004; Moon et al., 2004; Nelson and Nusse, 2004; Gordon

\footnotetext{
Received June 25, 2011; accepted July 20, 2011.

Author contributions: K.A.M. and K.J.R. designed research; K.A.M. performed research; K.A.M. and K.J.R. contributed unpublished reagents/analytic tools; K.A.M. and K.J.R. analyzed data; K.A.M. and K.J.R. wrote the paper.

Support for this work was provided by the NIH (DA019624, P30 NS055077); the Burroughs Wellcome Fund; the National Science Foundation (NSF) (GRFP DGE-0234618); the Center for Behavioral Neuroscience, a Science and Technology Center of the NSF, under Agreement \#IBN-9876754; National Primate Research Center Base Grant \#RR-00165; and the Animal Resource Program at NIH. We thank Dennis C. Choi, PhD, for his invaluable assistance with these studies.

The authors declare no competing financial interests.

Correspondence should be addressed to Dr. Kerry J. Ressler, Howard Hughes Medical Institute and Department of Psychiatry and Behavioral Sciences, Center for Behavioral Neuroscience Yerkes Research Center, Emory University, 954 Gatewood Drive, Atlanta, GA 30329. E-mail: kressle@emory.edu.

DOI:10.1523/JNEUROSCI.3248-11.2011

Copyright $\odot 2011$ the authors $\quad 0270-6474 / 11 / 3113057-11 \$ 15.00 / 0$
}

and Nusse, 2006). Alternatively, $\beta$-catenin also complexes with the cytoplasmic domain of cadherin. Upon differential phosphorylation, the $\beta$-catenin/cadherin complex dissociates, leading to the transient destabilization of synapses required for new synapse formation (Bamji et al., 2006; Arikkath and Reichardt, 2008).

The role of Wnt and $\mathrm{Wnt} / \beta$-catenin signaling in neuronal and synaptic development is increasingly well established. The addition of Wnt7 to cultured cerebellar granule cells and hippocampal neurons increases axonal spreading and branching, as well as promoting presynaptic assembly and synaptic vesicle accumulation (Lucas and Salinas, 1997; Hall et al., 2000; Ahmad-Annuar et al., 2006). Furthermore, the addition of Wnt 3 to sensory neurons in culture results in growth cone enlargement and increased axonal branching (Krylova et al., 2002). These data suggest that Wnts function in a retrograde manner to regulate presynaptic remodeling during the development of synapses. In adults, burgeoning evidence is building suggesting that dysregulation of Wnt signaling is associated with cognitive disorders, including schizophrenia and Alzheimer's disease (De Ferrari and Moon, 2006). Together, these data suggest that Wnts may play a role in adults beyond initial brain development.

Despite these findings, the functional role of the Wnt signaling pathway in adult neural circuits remains uncertain. Recent in vitro and slice physiology approaches have shown that Wnts may function in synaptic transmission and activity-dependent synaptic plasticity (Chen et al., 2006; Wayman et al., 2006). However, there is no evidence to date on the role of Wnt signaling in vivo underlying learning and memory formation in animals. We have previously shown that $\beta$-catenin signaling is required for fear memory formation in vivo, and transient dissociation of the 
$\beta$-catenin/cadherin complex is associated with the consolidation of new fear memories (Maguschak and Ressler, 2008). Given the evidence that $\beta$-catenin regulation is critical for memory formation, we hypothesized that Wnt regulation is required for $\beta$-catenin stability and regulation of synaptic plasticity in vivo. Here, using a variety of molecular, genetic and pharmacological manipulations, we demonstrate that dynamic $\mathrm{Wnt} / \beta$-catenin signaling may be an important pathway regulating long-term memory formation in adults.

\section{Materials and Methods}

Animals

Adult male C57BL/6J mice (The Jackson Laboratory) were used for all experiments. Mice were housed four per cage in a temperaturecontrolled $\left(24^{\circ} \mathrm{C}\right)$ animal colony, with ad libitum access to food and water, on a $12 \mathrm{~h}$ light-dark cycle, with all behavioral procedures done during the light cycle. All procedures used were approved by the Institutional Animal Care and Use Committee of Emory University and in compliance with National Institutes of Health $(\mathrm{NIH})$ guidelines for the care and use of laboratory animals.

\section{Stereotaxic surgery and infusion of peptides}

Mice were anesthetized by intraperitoneal injections of a ketamineDomitor (medetomidine) mixture and placed in a stereotaxic apparatus. Small holes were drilled into the skull and $6 \mathrm{~mm}$ stainless-steel guide cannulas (Plastics One) were lowered bilaterally in to the basolateral amygdala (BLA). BLA coordinates were as follows: anteroposterior, -1.8 ; dorsoventral, -4.9 ; mediolateral, \pm 3.2 relative to bregma. Dorsoventral coordinates were measured from the skull surface with the internal cannula extending $2 \mathrm{~mm}$ beyond the end of the guide cannula. Coordinates were based on the mouse brain atlas of Paxinos and Franklin (2004). The guide cannula was fixed to the skull using dental acrylic and jeweler's screws and dummy cannulas (Plastics One) were inserted into each guide cannula to prevent clogging. All animals were allowed to recover for $7 \mathrm{~d}$ before testing. During this time, mice were handled daily for acclimation and inspection of cannula fixture.

Animals were infused with either Dickkopf-1 (R\&D Systems) (100 ng/ side), Wnt1 (AbD Serotec) (100 ng/side), or PBS (vehicle). Infusions of $1.0 \mu \mathrm{l}$ were made using an injection cannula (33 gauge cannula, Plastics One), which extended $2.0 \mathrm{~mm}$ beyond the tip of the guide cannula. Peptide was delivered manually with a $5 \mu$ l Hamilton syringe attached to the injection cannula via polyethylene tubing (PE-10). Administration of a volume of $1.0 \mu \mathrm{l} / \mathrm{side}$ was delivered over a period of $60 \mathrm{~s}$ by slowly turning the microsyringe plunger. After each infusion, the injection cannula was allowed to remain for $2 \mathrm{~min}$. Visualization of injection sites was performed postmortem to verify the location of peptide infusion.

Schematic diagrams of extent of infusions were performed on Dkk-1 infused mice. Following all behavioral studies, mice were reinjected with $1.0 \mu \mathrm{l}$ of Dkk-1 30 min before perfusion with $4 \%$ paraformaldehyde to observe the likely extent of infusion during the behavioral studies. After fixation, brains were equilibrated in $30 \%$ sucrose, sectioned on a cryostat, and then processed for immunohistochemistry as outlined below. Sections were examined with a $4 \times$ objective on a light microscope and extent of Dkk-1 staining was drawn on Paxinos and Franklin (2004) mouse amygdala coordinates, as illustrated in Figure $3 a$.

\section{Immunoprecipitation and immunoblotting}

After behavioral procedures, brains were blocked rapidly and kept frozen at $-80^{\circ} \mathrm{C}$. Bilateral amygdala punches were obtained and homogenized. For immunoprecipitation experiments, solubilized proteins were incubated with Protein A/G PLUS-Agarose beads (Santa Cruz Biotechnology) and centrifuged. Protein A/G PLUS-Agarose beads and antibody to $\beta$-catenin (1:200, Cell Signaling Technology) were then added to the supernatant of each protein sample, incubated overnight at $4^{\circ} \mathrm{C}$, and washed before Western blot analyses.

For immunoblotting, $25 \mu \mathrm{g}$ of protein per mouse were electrophoretically separated by SDS-PAGE, transferred onto nitrocellulose membranes (Bio-Rad), blocked for $1 \mathrm{~h}$ in $2 \%$ nonfat dry milk, $0.1 \%$ Tween 20 , $50 \mathrm{~mm} \mathrm{NaCl}, 10 \mathrm{~mm}$ HEPES, pH 7.4. Membranes were incubated in primary antibody overnight at $4^{\circ} \mathrm{C}$. Antibodies to the following proteins were used: $\beta$-catenin (1:500, BD Biosciences) and pan-cadherin (1:1000, Cell Signaling Technology). Membranes were washed and incubated with a horseradish peroxidase-labeled secondary antibody (1:5000, Vector) and then detected by SuperSignal West Chemiluminescence (Pierce) in an Alpha Innotech Fluorchem imaging system (Alpha Innotech).

\section{Immunohistochemistry}

Brain sections $(40 \mu \mathrm{m})$ were blocked with $0.5 \mathrm{M}$ PBS and $0.5 \%$ Triton $\mathrm{X}-100$, and incubated in a 1:100 dilution of primary Dkk-1 (Santa Cruz Biotechnology) or Wnt1 (Santa Cruz Biotechnology) antibodies overnight at $4^{\circ} \mathrm{C}$. Sections were then washed with PBS and bathed in a 1:500 dilution of secondary antibody for $2 \mathrm{~h}$. Avidin-biotin complexes were amplified using a standard Vectastain Elite $\mathrm{ABC}$ kit and visualized with diaminobenzidine $(\mathrm{DAB})$ peroxidase staining.

\section{Behavioral studies}

Open-field behavior. The open field consisted of a box $(27.9 \mathrm{~cm} \times 27.9 \mathrm{~cm})$ made of Plexiglas. The mice were placed in the periphery of the arena at the start of the $10 \mathrm{~min}$ test period. At the end of the test, the animal was returned to its home cage. The anxiolytic-like effects were evaluated by computing percentage of time mice spent in the central zone of the open field. The central zone was defined as the central compartment of the floor centrally located $6 \mathrm{~cm}$ from the perimeter of the chamber walls. All testing was conducted under standard room lighting. Activity data were obtained and analyzed using the Open Field Activity Software (Med Associates).

Fear conditioning apparatus. Mice were fear conditioned in eight identical startle response systems (SR-LAB, San Diego Instruments). Each system consisted of a nonrestrictive Plexiglas cylinder $(5.5 \mathrm{~cm}$ in diameter and $13 \mathrm{~cm}$ long) mounted on a Plexiglas platform and located in a ventilated, sound-attenuated chamber. Cylinder movements were sampled each millisecond by a piezoelectric accelerometer mounted under each platform. The footshock unconditioned stimulus (US) was generated by a programmable animal shocker (San Diego Instruments) located outside the isolation chambers and was delivered through the cage floor bars. The conditioned stimulus (CS) was a tone delivered by a speaker located $\sim 15 \mathrm{~cm}$ above the chambers. Sound intensities were measured by an audiometer (Radio Shack). Stimuli presentation and data acquisition were controlled, digitized, and stored by a Dell computer using SR-LAB software.

Fear conditioning. After $5 \mathrm{~d}$ of exposure to the conditioning chambers, mice were placed in the chamber, and after 5 min presented with five tone-shock pairings at an intertrial interval (ITI) of $5 \mathrm{~min}$. Each pairing consisted of a $30 \mathrm{~s}$ tone $(6 \mathrm{kHz}, 85 \mathrm{db}, \mathrm{CS})$ that terminated with a $0.5 \mathrm{~s}$ footshock (1.0 mA, except where noted; US). Freezing in startle-reflex chambers during fear acquisition was assessed as described previously (Maguschak and Ressler, 2008). Forty-eight hours after training, mice were tested for freezing in a separate context: Med Associates rodent modular test chambers with an inside volume of $30.5 \mathrm{~cm} \times 24.1 \mathrm{~cm} \times$ $21.0 \mathrm{~cm}$. Three minutes later, 15 conditioned stimulus tones $(6 \mathrm{kHz}, 85 \mathrm{db})$ with an ITI of $1.5 \mathrm{~min}$ were delivered through a high-frequency speaker attached to the side of each chamber. Percentage time spent freezing during the conditioned stimulus presentation was calculated for each mouse using FreezeFrame video monitoring software (ACT-100; Coulbourn Instruments), using settings that were previously calibrated to levels of observed freezing. For the short-term memory test, mice were trained as above, with peptide infused $(1.0 \mu \mathrm{l}$ infusions bilaterally targeting lateral/basolateral amygdala) $15 \mathrm{~min}$ before fear training. Mice were then tested for freezing in the presence of 5 tones at $1 \mathrm{~h}$ after training. For the long-term memory expression test, mice were trained as above with a $12 \mathrm{kHz}$ tone, and $48 \mathrm{~h}$ later were tested for fear expression with 15 tones. Fifteen minutes before fear testing, mice were infused with $1.0 \mu \mathrm{l}$ of vehicle, Dkk-1, or Wnt1.

\section{RNA extraction and cDNA synthesis}

RNA isolation was performed using the Qiagen RNeasy Micro Kit for animal tissues (Qiagen). In short, amygdala punches were lysed and then homogenized. After centrifugation, ethanol was added to the lysates, and the samples were loaded onto the column, followed by DNase treatment. The columns were then washed to remove DNase and any other contaminants, and the remaining pure, concentrated RNA was eluted in RNasefree water. A $1.0 \mu \mathrm{g}$ quantity of total RNA was reverse transcribed in a 
Table 1. Temporal changes, expressed as fold regulation, in the expression of 84 genes related to Wnt-mediated signaling following fear conditioning

\begin{tabular}{|l|l|l|l|l|l|l|}
\hline Symbol & GeneBank $\mathbf{0} \mathbf{h}$ & $\mathbf{0 . 5} \mathbf{h}$ & $\mathbf{2} \mathbf{h}$ & $\mathbf{4} \mathbf{h}$ & $\mathbf{1 2} \mathbf{h}$ & $\mathbf{2 4} \mathbf{h}$ \\
\hline Fosl1 & NM_010235 & & & & & \\
\hline Wnt1 & NM_021279 & & & & & \\
\hline T & NM_009309 & & & & & \\
\hline Wnt16 & NM_053116 & & & & & \\
\hline Wisp1 & NM_018865 & & & & & \\
\hline Fgf4 & NM_010202 & & & & & \\
\hline Wnt6 & NM_009526 & & & & & \\
\hline Fzd8 & NM_008058 & & & & & \\
\hline Pitx2 & NM_011098 & & & & & \\
\hline Wnt11 & NM_009519 & & & & & \\
\hline Wnt7b & NM_009528 & & & & & \\
\hline Pygo1 & XM_134865 & & & & & \\
\hline Wnt9a & NM_139298 & & & & & \\
\hline Ctbp2 & NM_009980 & & & & & \\
\hline Myc & NM_010849 & & & & & \\
\hline Wnt10a & NM_009518 & & & & & \\
\hline Wif1 & NM_011915 & & & & & \\
\hline Wnt3 & NM_009521 & & & & & \\
\hline Apc & NM_007462 & & & & & \\
\hline Fbxw4 & NM_013907 & & & & & \\
\hline Wnt5a & NM_009524 & & & & & \\
\hline Ccnd2 & NM_009829 & & & & & \\
\hline Gsk3b & NM_019827 & & & & & \\
\hline Frat1 & NM_008043 & & & & & \\
\hline Tcf3 & NM_009332 & & & & & \\
\hline Sox17 & NM_011441 & & & & & \\
\hline Ctbp1 & NM_013502 & & & & & \\
\hline Csnk1d & NM_139059 & & & & & \\
\hline Wnt2b & NM_009520 & & & & & \\
\hline Daam1 & NM_172464 & & & & & \\
\hline Bc19 & NM_029933 & & & & & \\
\hline Sfrp1 & NM_013834 & & & & & \\
\hline Tcf7 & NM_009331 & & & & & \\
\hline Frzb & NM_011356 & & & & & \\
\hline Jun & NM_010591 & & & & & \\
\hline Nkd11 & NM_027280 & & & & & \\
\hline Wnt7a & NM_009527 & & & & & \\
\hline Fbxw2 & NM_013890 & & & & & \\
\hline Dvl2 & NM_007888 & & & & & \\
\hline Fzd3 & NM_021458 & & & & & \\
\hline Aes & NM_010347 & & & & & \\
\hline Ctnnbip1 NM_023465 & & & & & \\
\hline
\end{tabular}

\begin{tabular}{|c|c|c|c|c|c|}
\hline Symbol & GeneBank & \begin{tabular}{|l|l|l|l}
$0 h$ & $0.5 h$ & $2 h$ \\
\end{tabular} & $4 \mathrm{~h}$ & $12 \mathrm{~h}$ & $24 \mathrm{~h}$ \\
\hline Wnt4 & NM_009523 & & & & \\
\hline Ep 300 & NM_177821 & & & & \\
\hline Tle1 & NM_011599 & & & & \\
\hline Wnt5b & NM_009525 & & & & \\
\hline Sfrp2 & NM_009144 & & & & \\
\hline Fzd1 & NM_021457 & & & & \\
\hline Dvl1 & NM_010091 & & & & \\
\hline Lrp5 & NM_008513 & & & & \\
\hline Sfrp4 & NM_016687 & & & & \\
\hline Kremen1 & 1 NM_032396 & & & & \\
\hline Csnk1a1 & NM_146087 & & & & \\
\hline Ctnnb1 & NM_007614 & & & & \\
\hline Porcn & NM_023638 & & & & \\
\hline Axin1 & NM_009733 & & & & \\
\hline Btrc & NM_009771 & & & & \\
\hline Senp2 & NM_029457 & & & & \\
\hline Csnk2a1 & NM_007788 & & & & \\
\hline Ppp2ca & NM_019411 & & & & \\
\hline Nlk & NM_008702 & & & & \\
\hline Cend1 & NM_007631 & & & & \\
\hline Ppp2r1a & NM_016891 & & & & \\
\hline Ppp2r5d & NM_009358 & & & & \\
\hline Lrp6 & NM_008514 & & & & \\
\hline Rhou & NM_133955 & & & & \\
\hline Fbxw11 & NM_134015 & & & & \\
\hline Slc9a3r1 & NM_012030 & & & & \\
\hline Wnt8a & NM_009290 & & & & \\
\hline Fzd2 & NM_020510 & & & & \\
\hline Wnt8b & NM_011720 & & & & \\
\hline Foxn1 & NM_008238 & & & & \\
\hline Cond3 & NM_007632 & & & & \\
\hline Lef1 & NM_010703 & & & & \\
\hline Fzd6 & NM_008056 & & & & \\
\hline Dixdc1 & NM_178118 & & & & \\
\hline Wnt2 & NM_023653 & & & & \\
\hline Dkk1 & NM_010051 & & & & \\
\hline Fzd4 & NM_008055 & & & & \\
\hline Fzd7 & NM_008057 & & & & \\
\hline Fshb & NM_008045 & & & & \\
\hline Wnt3a & NM_009522 & & & & \\
\hline Tle2 & NM_019725 & & & & \\
\hline Fzd5 & NM_022721 & & & & \\
\hline
\end{tabular}

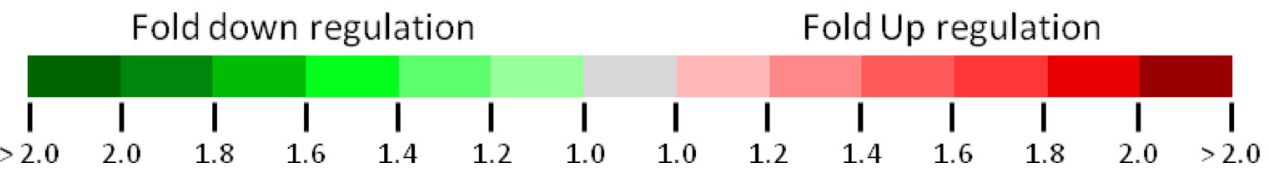

final reaction mix of $20 \mu \mathrm{l}$ using $\mathrm{RT}^{2}$ First Strand Kit (SuperArray Bioscience) according to the manufacturer's instructions. cDNA was diluted by adding RNase-free water.

Real-time PCR

Real-time PCR was performed using $2 \times$ SuperArray RT qPCR Master Mix (SA Biosciences) and RT ${ }^{2}$ Profiler PCR Array System (PAMM-043, SA Biosciences) or mouse Wntl PCR primer stock (SA Biosciences). The Wnt Pathway array consisted of 84 genes related to Wnt-mediated signal transduction, along with appropriate RNA quality controls, in 96-well plates. For each array, amygdala samples from each experimental group were pooled together. For the Wnt1 PCRs, amygdala samples were analyzed individually. Thermal cycling parameters were $10 \mathrm{~min}$ at $95^{\circ} \mathrm{C}$, followed by 40 cycles of amplifications for $15 \mathrm{~s}$ at $95^{\circ} \mathrm{C}, 1 \mathrm{~min}$ at $60^{\circ} \mathrm{C}$. A dissociation stage, consisting of $15 \mathrm{~s}$ at $95^{\circ} \mathrm{C}, 1 \mathrm{~min}$ at $60^{\circ} \mathrm{C}$, and $15 \mathrm{~s}$ at $95^{\circ} \mathrm{C}$, was added at the end. Quantification of mRNA was performed using the Applied Biosystems 7500 Real-Time PCR System. Relative levels of mRNA expression were normalized in all the samples with expression levels of glyceraldehyde-3-phosphate dehydrogenase (GAPDH). For the Wnt1 PCRs, the $\Delta \Delta$ Cts were compared across groups. Figure $3 A$ shows the mean \pm SEM of the $\Delta \Delta \mathrm{Ct}$ values, and Figure $3 B$ shows the mean fold change following previously described methods (Livak and Schmittgen, 2001).

\section{In situ hybridization}

In situ hybridization was performed and quantified as previously described (Ressler et al., 2002; Maguschak and Ressler, 2008). The Wnt1 
clone was obtained by inserting the $144 \mathrm{bp}$ Wnt1 RT PCR product from above into the pCR2.1-TOPO vector (Invitrogen). After sequence verification, the cloned cDNA was linearized and antisense riboprobes were generated using T7 RNA polymerase and $\left[{ }^{35} \mathrm{~S}\right]$-UTP in the reaction. After a stringent wash protocol, slides were apposed to Biomax MR autoradiography film (Eastman Kodak). Hybridization density of Wnt 1 mRNA in the BLA was assessed using the mean luminosity function of Adobe Photoshop.

Data analysis

Statistically significant differences were determined by Student's $t$ test or ANOVA, with post hoc least-squares difference tests for multiple comparisons. The results are presented as mean \pm SEM.

\section{Results}

\section{Genes in Wnt-mediated signaling are} altered during memory formation

We first wished to examine whether Wntrelated genes showed dynamic alterations in conjunction with memory formation. Thus we performed a series of mRNA expression arrays focusing on 84 Wnt-related genes, to identify whether any genes were endogenously regulated within the amygdala during the memory consolidation period following fear learning.

Following $5 \mathrm{~d}$ of habituation to the conditioning chambers, behaviorally naive mice received five tone-shock pairings. A context control group was placed in the conditioning chambers for the same amount of time, but no stimuli were presented. We collected brains from the control mice $2 \mathrm{~h}$ after context exposure; brains from the trained mice were collected immediately or $0.5,2$, 4,12 , or $24 \mathrm{~h}$ after conditioning.

Bilateral amygdala from the above mice were dissected and RNA was isolated. Equal amounts of RNA from each animal were then pooled into seven groups, one group for each time point, including context control. Total RNA was converted to cDNA, and the samples were then subjected to gene expression analysis using rtPCR arrays containing genes involved in Wnt signaling, as well as housekeeping genes.

The results from the PCR arrays showed multiple patterns and amplitudes of modulation for the expression of Wnt genes following learning (Table 1). We did not find any changes in the housekeeping genes across groups. We found that 15 of $17 \mathrm{Wnts}$ (and $>50$ of all Wnt-related genes examined) decrease relative to control, immediately following fear conditioning (Fig. 1A, Table 1). Furthermore, the expression patterns for most of the Wnts could be assigned to one of two categories at the 0 and $0.5 \mathrm{~h}$ time points, the 2 and $4 \mathrm{~h}$ time points, and the 12 and $24 \mathrm{~h}$ time points (Fig. 1). Together these data suggest that transcriptional regulation or mRNA stability of Wnt genes are highly correlated with new memory formation within the amygdala. Furthermore, the majority of Wnts show a rapid decrease in expression during the very early phase of fear memory consolidation, followed by a more variable return to normal expression levels over time.

\section{Wnt1 gene expression changes with learning}

We first replicated the initial finding above by performing quantitative real-time PCR (qPCR) on the Wnt-related genes that were most altered with fear conditioning. Among all the genes examined in the PCR array and the follow-up qPCR study, Wnt1 showed the greatest fold change following fear conditioning. Therefore, we wanted to confirm and replicate this initial finding in an additional cohort of animals. We then performed another experiment with a new series of naive mice using qPCR specifically focused on the Wntl gene. After $5 \mathrm{~d}$ of habituation to the conditioning chambers, mice were exposed to the context alone, to unpaired tone and shock presentations, or to five paired tone and shock presentations. The mice were then killed as above. RNA from both amygdala of each mouse was prepared, and then analyzed by qPCR. We found that the pattern of expression from the QPCR results closely resembled the pattern observed from the PCR array (Fig. 2A,B). More specifically, we observed a significant decrease in Wntl gene expression immediately following fear conditioning, compared to animals exposed to the context, without any stimuli presentations (ANOVA, $F_{(7,83)}=3.18, p<$ 0.01 ; post hoc pairwise comparisons: $0 \mathrm{~h}$ is significantly decreased from context, unpaired, and 2, 4, 12, and $24 \mathrm{~h}$ ). This effect does not appear to be due to the presentation of the tone or the stress of shock alone, since the unpaired group did not differ significantly from the context group $(p>0.1)$.

To further validate our Wnt1 results, we fear conditioned a separate group of animals and killed the mice at the same time points as above. This time, however, we analyzed the expression of Wnt1 by in situ hybridization (Fig. $2 C-F$ ). This method allowed us to look more specifically at the regional expression pattern of Wnt1, focusing on the BLA. Again, we found that Wnt1 mRNA in the BLA was altered with fear conditioning, similar to the pattern observed in both the array and the qPCR $\left(F_{(5,47)}=\right.$ 18.36, $p<0.01$, Fig. $2 G$ ). Post hoc least-squares difference analyses indicated a significant decrease in Wnt1 mRNA expression immediately after and $0.5,2$, and $4 \mathrm{~h}$ after fear conditioning $(p<0.01)$ compared to context animals and animals killed $24 \mathrm{~h}$ after conditioning. We did not find any significant differences in Wnt1 mRNA in the striatum $(p>0.1)$, a brain region not involved in cue-dependent fear conditioning. Interestingly, the pattern that was observed was remarkably similar to the $\beta$-catenin/cadherin destabilization time course that we 
a
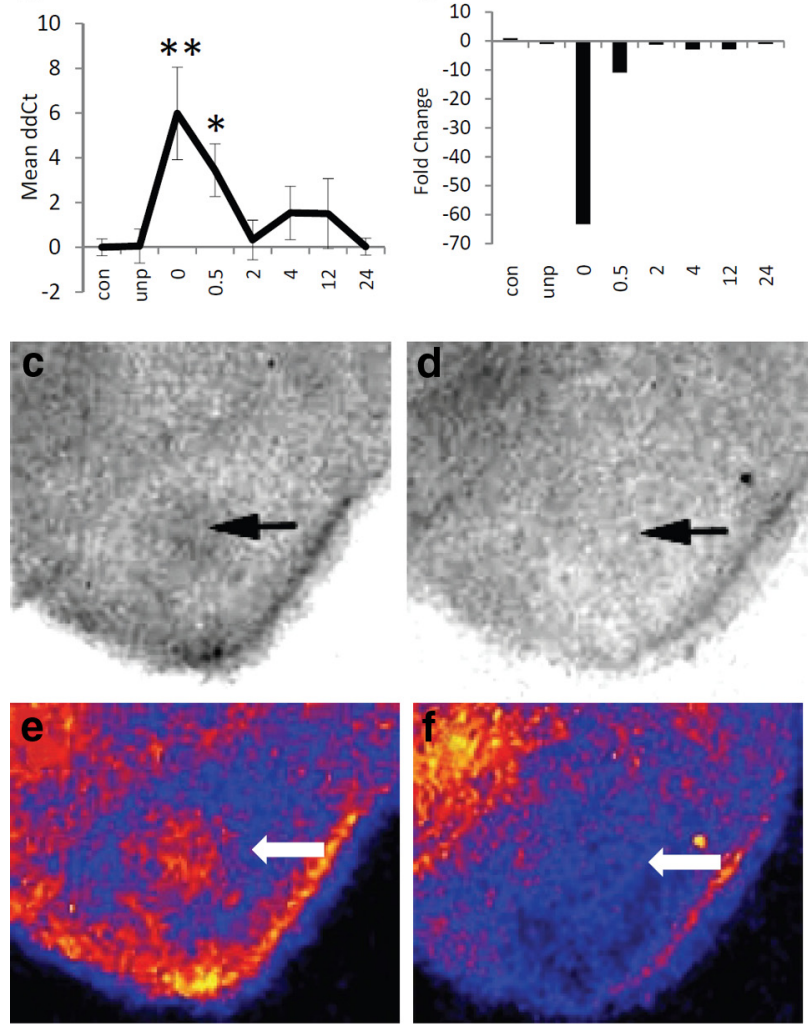

g

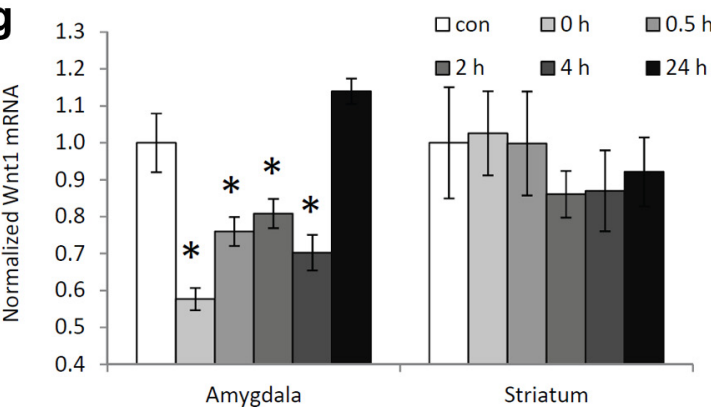

Figure 2. Wnt $1 \mathrm{mRNA}$ expression in the amygdala. $\boldsymbol{a}$, Quantitative RT-PCR data showing the mean $\Delta \Delta$ Ct values \pm SEM across different conditions. Note that at the 0 (immediate) time point after fear conditioning, detecting the Wnt mRNA signal took on average six PCR cycles more than in the control and unpaired conditions. $\boldsymbol{b}$, The same data as in $\boldsymbol{a}$ presented as mean fold upregulation or downregulation of Wnt1 mRNA compared to context-exposed mice. $n=$ 14 for context, 7 for unpaired, 11 for 0 and $0.5 \mathrm{~h}, 12$ for $2,4,12$, and $24 \mathrm{~h} .{ }^{*} p<0.05,{ }^{* *} p<0.01$, ANOVA with LSD post hoc analyses. $\boldsymbol{c}, \boldsymbol{d}$, Autoradiography images of ${ }^{35}$-labeled Wnt 7 riboprobe hybridized, in situ, to amygdala from mice killed immediately after training (d) or after context exposure (c).e, $\boldsymbol{f}$, Pseudocolored images of $\boldsymbol{c}$ and $\boldsymbol{d}$, respectively. Yellow, Highest expression; blue-black, lowest expression. Arrows point to amygdala. $g$, Relative expression of Wnt1 mRNA in the amygdala and striatum, normalized to expression in context-exposed mice. $n=8$ per group. Data are mean $\pm S E M ;{ }^{*} p<0.01$, ANOVA with post hoc analyses.

have previously reported (Maguschak and Ressler, 2008), suggesting that Wnt1 regulation within the amygdala during fear consolidation may be highly correlated with the previous $\beta$-catenin effects we found to be required for normal memory formation.

\section{Preventing Wnt-mediated signaling impairs memory formation}

Given the above data on the importance of dynamic Wnt regulation, immediate decreases followed by normalization, we sought to examine the role of the $\mathrm{Wnt} / \beta$-catenin pathway in the amygdala of adult mice. We used Pavlovian cue-dependent fear conditioning as a model of learning and memory which is highly dependent on the amygdala. We first wished to determine whether blocking the Wnt/ $\beta$-catenin pathway would affect memory formation. Dickkopf-1 (Dkk-1) is a known extracellular antagonist of the Wnt pathway (Diep et al., 2004). It is expressed at low levels in the adult brain, but when present, promotes the internalization of LRP6, thereby, preventing Wnt from binding to its coreceptor.

To examine the effect of deregulating normal Wnt signaling in the amygdala, cannula were bilaterally implanted in the basolateral amygdala, and either Dkk-1 (100 ng/side) or saline were infused into mice. The presence and spread of the Dkk-1 peptide was verified by immunohistochemistry (Fig. $3 A, B$ ), and there did not appear to be any histological abnormalities as assessed by Nissl stain (Fig. 3C,D) due to the infusion.

After confirming that we could increase the expression of Dkk-1 within the amygdala, we first examined whether Dkk-1 affected baseline emotional behavior or locomotion. We injected Dkk-1 before open-field behavior, and found that there was no difference $(p>0.1)$ between Dkk-1 on mouse locomotion or anxiety-related behavior as measured by distance traveled and time spent in the center compared to time in the surround (Fig. 3E).

We then tested whether the presence of this peptide interfered with memory formation. After $5 \mathrm{~d}$ of habituation to the conditioning chambers to minimize context effects, mice received infusions of either Dkk-1 or saline bilaterally into the amygdala, and were fear conditioned $15 \mathrm{~min}$ after infusion with five toneshock pairings. Throughout the training paradigm, we measured freezing behavior during each tone presentation (conditioned stimulus) before the presentation of footshock. We found a significant main effect of time across all mice $\left(F_{(5,90)}=35.75, p<\right.$ 0.01 , Fig. $3 F$ ); however, there was no main effect of treatment $(p>0.1)$. These data demonstrate that the Dkk-1 peptide does not alter baseline locomotion or anxiety-like behavior, nor does it affect the acquisition of conditioned fear memory.

Forty-eight hours after cue fear conditioning, mice were placed in a different chamber and presented with 15 conditioned stimulus tones. The mean percentage time spent freezing during these tones was recorded and used as a measure of conditioned fear. Mice that received Dkk-1 before fear training now showed significantly less fear than did mice that had received saline $\left(t_{(10.10)}=3.62, p<0.01\right.$, Fig. $\left.3 G\right)$. This deficit in fear retention was present throughout the testing session $\left(F_{(1,18)}=13.08, p<\right.$ 0.01 , Fig. $3 H$ ), as measured by percentage time spent freezing in three blocks of five trials: block $1\left(t_{(10.43)}=3.33, p<0.01\right)$, block $2\left(t_{(10.27)}=3.76, p<0.01\right)$, and block $3\left(t_{(10.98)}=3.38, p<0.01\right)$. Furthermore, the deficit did not seem to be caused by effects on locomotor behavior, as the mice did not show any significant differences across groups in activity level or freezing behavior before the first conditioned stimulus. These data suggest that a nonspecific manipulation that decreased Wnt functioning during or soon after fear conditioning leads to decreases in the expression of fear behavior $48 \mathrm{~h}$ later, consistent with a role for Wnt signaling within the amygdala in memory formation or consolidation.

Increasing Wnt1 signaling impairs fear memory formation The mRNA expression data suggest that the transient decrease in Wnt1 expression immediately following fear conditioning is correlated with memory formation. Therefore, we examined whether preventing this transient decrease by replacing Wntl in 
the amygdala would produce deficits in memory formation. First, we infused either a Wntl peptide (100 ng/side) or saline and found that infusions did not produce any structural damage to the amygdala, as visualized by Nissl staining (Fig. $4 A, B$ ). We next examined whether Wnt1 would affect baseline locomotion or anxiety-like behaviors. We injected Wnt1 before open-field behavior and found that there was no difference $(p>0.1)$ between Wntl and vehicle on mouse locomotion (distance traveled) or anxiety-related behavior (time spent in the center compared to time in the surround) (Fig. 4C).

We then infused Wntl or saline immediately before and after fear conditioning to determine whether increasing Wntl affects memory formation. The intensity of the unconditioned stimulus was lowered to $0.6 \mathrm{~mA}$ to prevent ceiling effects on fear expression. We found that all mice were able to acquire fear equally $\left(F_{(5,125)}=\right.$ 35.36, $p<0.01$, Fig. $4 D$ ), regardless of whether they had saline or Wnt1 infused into the amygdala before conditioning $(p>0.1)$. However, when tested $48 \mathrm{~h}$ later, there was a significant difference between animals that had received vehicle or Wnt1 before training $\left(F_{(2,26)}=10.73, p<\right.$ $0.01)$. Post hoc analyses revealed that animals that had received Wnt1 before training froze significantly less compared to animals that had received either saline before training $(p<0.01)$, or Wntl after training $(p<0.01$, Fig. $4 E)$. This difference in fear retention across treatment was apparent throughout the testing session $\left(F_{(2,24)}=10.73, p<0.01\right.$, Fig. $\left.4 F\right)$. When examined in three blocks of five tone presentations each, post hoc analyses indicated that animals receiving Wnt 1 before training froze significantly less than animals receiving vehicle before and after training during block $1(p<0.01)$, block 2 $(p<0.01)$, and block $3(p<0.05)$. In addition, animals receiving Wnt 1 before training froze significantly less than animals receiving vehicle before and Wnt 1 after training for all blocks $(p<0.01)$. These data suggest that infusing Wnt1 into the amygdala, counteracting the normal rapid decrease in Wnt1, prevents fear memory formation. If Wntl is given following fear conditioning, however, after this critical period of transient endogenous Wnt decrease, then normal learning occurs. Thus, the rapid decrease in endogenous Wnt1 mRNA, which likely begins early in fear training and is observed immediately after conditioning, may be critical for the formation of fear memory.

\section{Wnt1 prevents learning-dependent disassociation between $\boldsymbol{\beta}$-catenin and cadherin}

We have shown that blocking Wnt signaling and preventing the Wntl decrease during or immediately following learning both
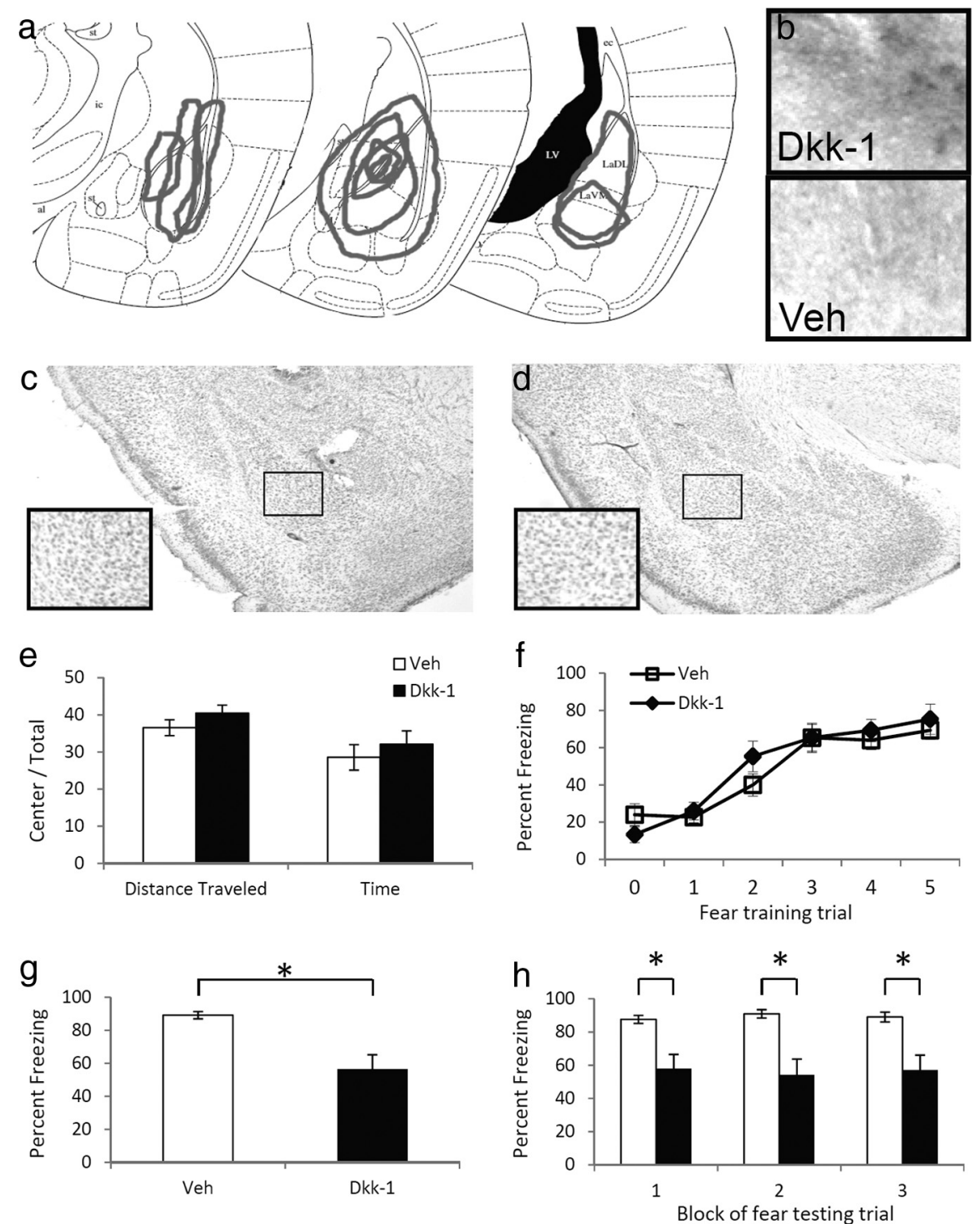

Figure 3. The effect of Dkk-1 in the amygdala on fear learning and memory. $\boldsymbol{a}$, Schematic diagram, based on Paxinos and ranklin (2004), illustrating the extent of infusions across animals via stereotaxic cannulae into the amygdala based on immunomals receiving bilateral amygdala injections of either Dkk-1 or vehicle. $\boldsymbol{c}, \boldsymbol{d}$, Cresyl violet staining of sections showing the . Percentage time spent freezing when tested $48 \mathrm{~h}$ after fear conditioning, and presented with 15 tone presentations. $\boldsymbol{h}$, Freezing data from $\boldsymbol{g}$, presented in three blocks of five tone presentations. $n=10$ per group. Data are mean $\pm \mathrm{SEM}^{*} p<0.01$, significant differences (two-tailed $t$ tests).

impair memory formation. One possible explanation for this apparent discrepancy would be if the rapid decrease and then normalization of Wnt signaling have equally important, but opposite effects on mechanisms of memory consolidation. To address this, we examined biochemical changes that may be occurring during consolidation at baseline and in Wnt1- and Dkk-1-treated animals.

Previous in vitro research has shown that Wnt1 increases cell-cell adhesion by promoting the binding of $\beta$-catenin to cadherin (Hinck et al., 1994). Our finding of a decrease in Wnt1 gene expression appears to be correlated with the rapid pattern of $\beta$-catenin/cadherin dissociation following learning. Since we have previously shown that the association between $\beta$-catenin and cadherin is decreased immediately following 

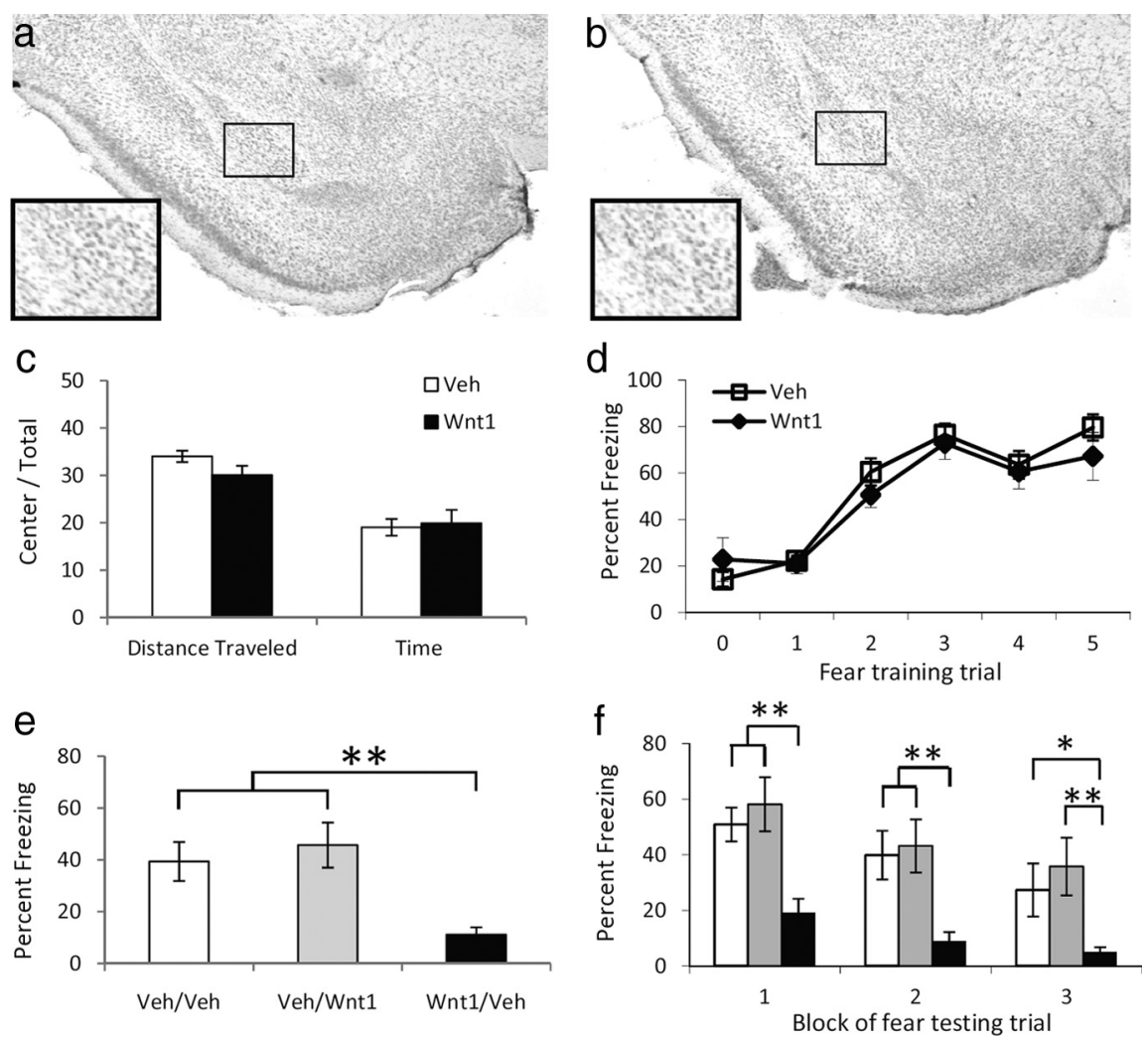

Figure 4. The effect of Wnt 1 in the amygdala on fear learning and memory. $\boldsymbol{a}, \boldsymbol{b}$, Cresyl violet staining of parallel sections showing the absence of damage in vehicle- $(\boldsymbol{a})$ or Wnt1- $(\boldsymbol{b})$ infected regions. $\boldsymbol{c}$, Activity measures of mice receiving injections of vehicle or Wnt1 and placed in an open-field apparatus for $10 \min . n=13$ for vehicle, $n=15$ for Wnt1. , Acquisition curve showing percentage time spent freezing during each tone before footshock presentation. $n=15$ for vehicle, $n=23$ for Wnt1. $\boldsymbol{e}, \boldsymbol{f}$, Animals were injected with either vehicle or Wnt1 before training, and vehicle or Wnt1 after training (Pre-training/Post-training). $\boldsymbol{e}$, Percentage time spent freezing when tested $48 \mathrm{~h}$ after fear conditioning, and presented with 15 tone presentations. $f$, Freezing data from $\boldsymbol{e}$, presented in three blocks of five tone presentations. White bars are Veh/Veh, gray bars are Veh/Wnt1, and black bars are Wnt1/Veh animals. For both $\boldsymbol{e}$ and $\boldsymbol{f}, n=8$ for Veh/Veh, $n=$ 7 for Veh/Wnt1, $n=12$ for Wnt1/Veh. Data are mean \pm SEM; ${ }^{* *} p<0.01,{ }^{*} p<0.05$, ANOVA with post hoc analyses.

learning, we first wanted to examine whether increasing Wnt1 before or soon after fear conditioning would prevent this observed dissociation.

We infused either Wnt1 (Wnt1_T) or saline (Veh_T) bilaterally into the amygdala before fear conditioning. A third control group was included, which received saline before context exposure, but did not receive any stimulus presentations (Veh_NT). In agreement with our previous results, all trained animals were able to equally acquire the fear during the conditioning $\left(F_{(5,145)}=26.59, p<0.01\right)$. In addition, animals receiving training froze significantly more across time compared to the untrained control group $\left(F_{(1,37)}=27.57, p<\right.$ 0.01 , Fig. $5 A)$. A subset of these animals was killed immediately after training or exposure to the context, and brains were collected. We then immunoprecipitated $\beta$-catenin from the amygdala and probed with an antibody to pan-cadherin. We found a significant main effect for treatment $\left(F_{(2,25)}=3.35\right.$, $p \leq 0.05)$. The amount of cadherin coimmunoprecipitated with $\beta$-catenin was significantly lower in trained mice immediately after conditioning than in context control mice as we had previously demonstrated $\left(t_{(13)}=2.68, p<0.5\right.$, Fig. $\left.5 B\right)$. Notably, we found that this decrease was abolished when Wnt 1 was injected into the amygdala before training $\left(_{(12.37)}=\right.$ $-2.89, p \leq 0.01$ ), preventing the normal learning-dependent transient decrease in Wnt1 expression. These results suggest that exogenous Wnt1 may impair memory formation by stabilizing $\beta$-catenin/ cadherin interactions during the early consolidation period, thus preventing the normal transient $\beta$-catenin/cadherin disassociation that occurs with transient Wnt1 depletion.

Previous in vitro research has shown that Dkk-1 decreases the accumulation of $\beta$-catenin and cadherin at cell membrane, resulting in a decrease in cell-cell adhesion (Kuang et al., 2009). Since we have previously shown that the association between $\beta$-catenin and cadherin is decreased immediately following learning, which then returns to baseline at $2 \mathrm{~h}$, we wanted to examine whether inhibiting Wnt signaling would prevent the reassociation of the $\beta$-catenin/cadherin complex at the $2 \mathrm{~h}$ time point.

We infused either saline or Dkk-1 bilaterally into the amygdala before context exposure or fear conditioning, and killed the animals $2 \mathrm{~h}$ later. We then collected the brains, immunoprecipitated $\beta$-catenin from the amygdala, and probed with an antibody to pan-cadherin. We found a significant main effect for treatment $\left(F_{(3,35)}=2.86, p \leq 0.05\right.$, Fig. $\left.5 C\right)$. Post hoc least-squares difference analyses indicated that the amount of cadherin coimmunoprecipitated with $\beta$-catenin was significantly lower in trained mice receiving injections of Dkk-1 before conditioning than in context control mice $(p<$ $0.01)$ or fear-conditioned mice $(p<0.05)$ receiving vehicle injections. These results suggest that exogenous Dkk-1 may impair memory formation by preventing the restabilization of the $\beta$-catenin/cadherin interaction during the early consolidation period.

\section{Dkk-1 and Wnt 1 have no effect on fear acquisition, short-term memory, or fear expression}

The above data suggest that Wnt1 expression is correlated with fear memory consolidation and that manipulating Wnt signaling disrupts long-term fear memories. However, it is possible that the effects are on short-term memory formation and not long-term memory consolidation. To address this question, another cohort of mice was infused with vehicle, Dkk-1, or Wnt1 as outlined above. As shown in Figure 6, we see no significant effect on the rate of acquisition of fear when these peptides are infused into bilateral amygdala sites as shown previously. Following fear acquisition, these mice were returned to their home cage. One hour after training, they received a short-term memory test, in which five tones were presented and freezing was measured. In contrast to the effects of Wntl and Dkk-1 on long-term memory consolidation, no differences were seen in this short-term memory test (Fig. 6B).

To further confirm that Wntl and Dkk-1 did not have an effect on sensory processing or on long-term memory expression, we examined the role of amygdala infusion with peptide on a long-term memory expression paradigm. Forty-eight hours fol- 

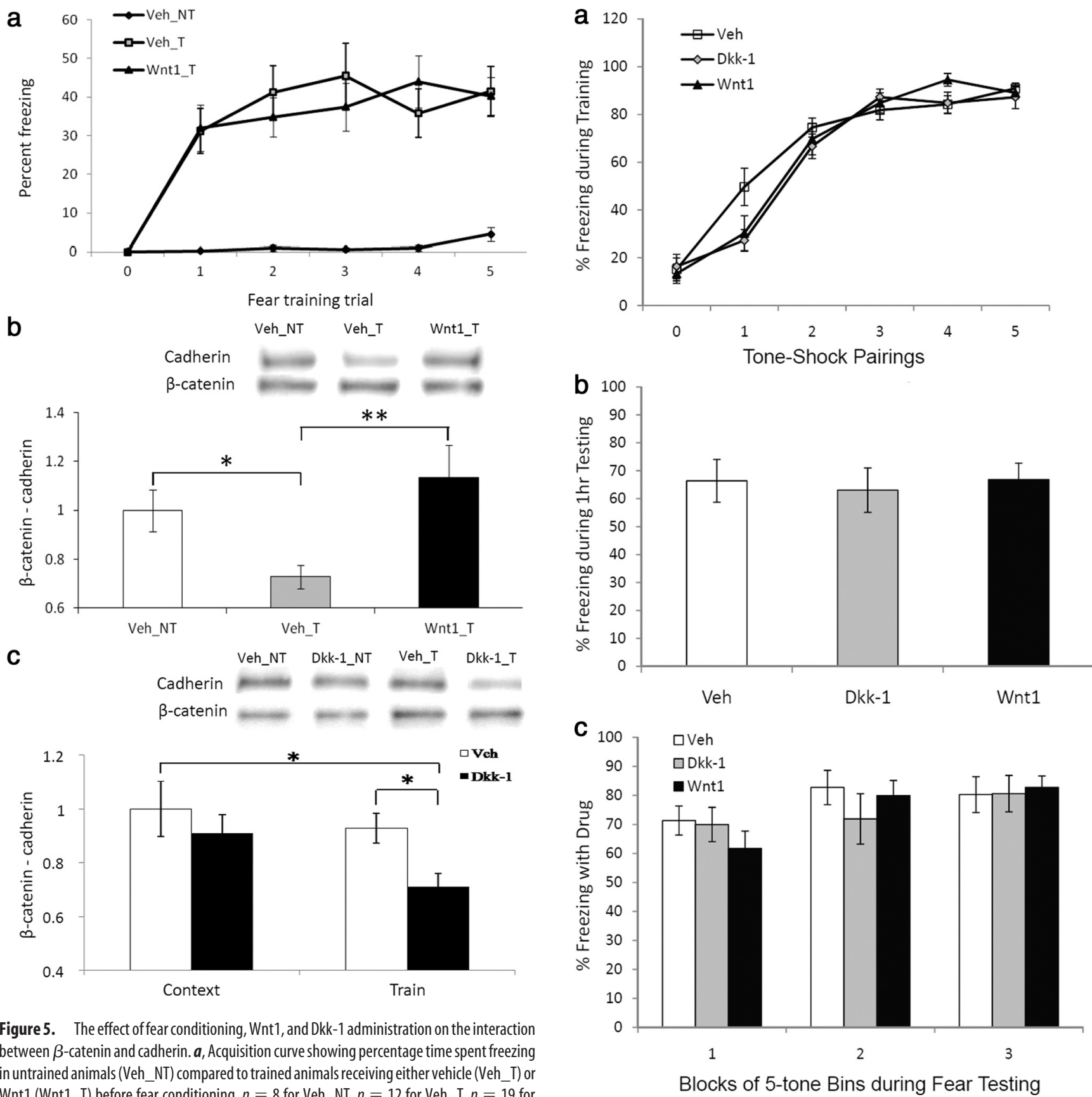

Figure 5. The effect of fear conditioning, Wnt1, and Dkk-1 administration on the interaction between $\beta$-catenin and cadherin. $\boldsymbol{a}$, Acquisition curve showing percentage time spent freezing in untrained animals (Veh_NT) compared to trained animals receiving either vehicle (Veh_T) or Wnt1 (Wnt1_T) before fear conditioning. $n=8$ for Veh_NT, $n=12$ for Veh_T, $n=19$ for Wnt1_T. $\boldsymbol{b}$, Qualitative and quantitative Western blot data showing a coimmunoprecipitation of cadherin from $\beta$-catenin. $n=8$ for Veh_NT, $n=7$ for Veh_T, $n=11$ for Wnt1_T, showing that Wnt1 prevents normal dissociation of $\beta$-catenin/cadherin interactions within $30 \mathrm{~min}$ of fear conditioning. c, Qualitative and quantitative Western blot data showing a coimmunoprecipitation of cadherin from $\beta$-catenin following vehicle or Dkk-1 treatment in context exposed ( $n=9$ Veh, $n=10$ Dkk-1) versus trained animals $(n=11$ Veh, $n=9 \mathrm{Dkk}-1)$, demonstrating that Dkk-1 prevents the restabilization of $\beta$-catenin/cadherin interactions $2 \mathrm{~h}$ after fear conditioning. Data are mean $\pm \mathrm{SEM},{ }^{*} p<0.05,{ }^{* *} p \leq 0.01$, ANOVA and two-tailed $t$ tests.

lowing training to five tone-shock pairings with a $12 \mathrm{kHz}$ tone, mice were tested for expression of conditioned fear (Fig. 6C). No effect of drug was seen on expression of conditioned freezing across three blocks of five tones each.

\section{Discussion}

Our data suggest that Wnt signaling in the amygdala plays an important role in long term memory formation. We showed that during the early consolidation of memory, a number of genes in

Figure 6. Dkk-1 and Wnt 1 infusions are not associated with altered fear acquisition, shortterm memory, or fear expression. $\boldsymbol{a}$, Mice were injected via stereotaxically placed cannulae within bilateral amygdala, with vehicle, Dkk-1, or Wnt1 ( $n=11$ per group) before fear conditioning with $5-6 \mathrm{kHz}$ tone-footshock pairings. No differences were seen in the freezing responses during fear training. $\boldsymbol{b}$, At $1 \mathrm{~h}$ following the above training, mice were tested in a short-term memory paradigm in which 5 tones were presented and freezing was measured. In contrast to the effects of Dkk-1 and Wnt1 on long-term memory consolidation, no differences were seen in this short term memory test. c, Forty-eight hours following training to five toneshock pairings with a $12 \mathrm{kHz}$ tone, mice were tested for expression of conditioned fear. In this study, mice were injected via cannulae bilaterally into the amygdala, with vehicle $(n=11)$, Dkk-1 $(n=11)$, or Wnt1 ( $n=11$ ) before testing. No effect of drug was seen on expression of conditioned freezing across three blocks of five tones each.

the Wnt signaling pathway are dynamically regulated with fear conditioning. The most striking difference was a rapid downregulation of many Wnt genes, with Wnt 1 having the most robust effect, immediately after conditioning, which was found across 

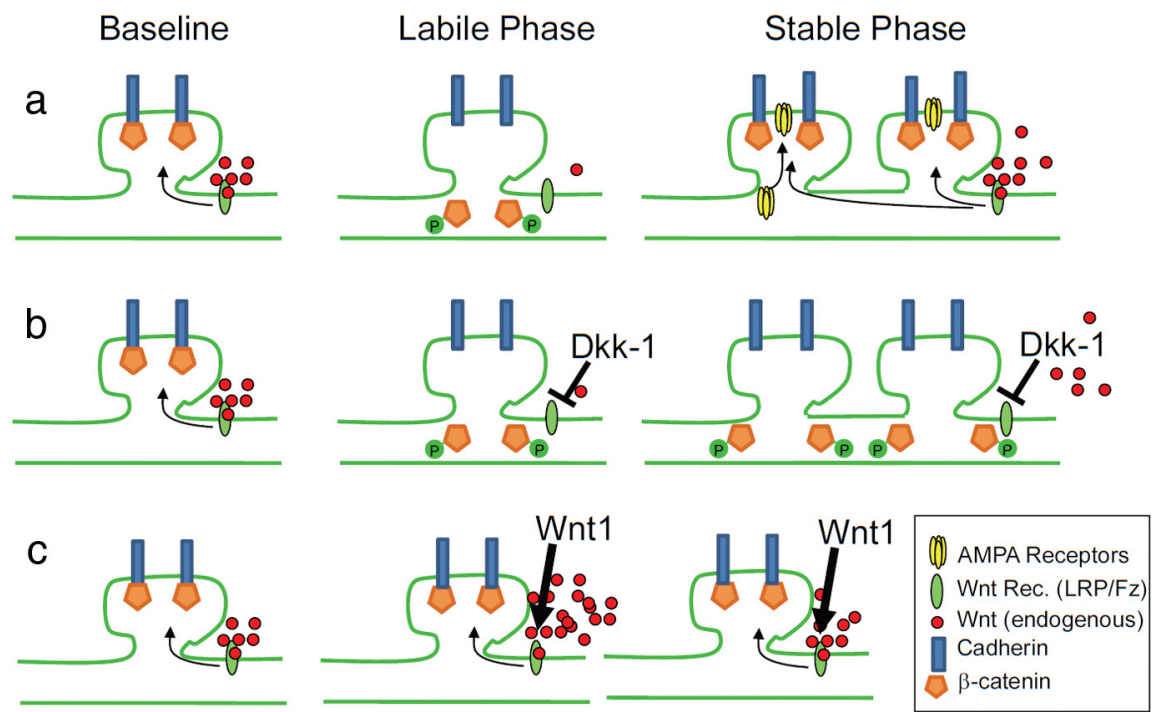

Figure 7. Schematic representation of the role of Wnt/ $\beta$-catenin signaling in producing the labile and stable phases of memory formation. $\boldsymbol{a}$, Baseline levels of Wnt stabilize $\beta$-catenin/Cadherin synaptic stability, transient Wnt decrease during the labile phase allowing for synapse rearrangement, followed by Wnt normalization, which may mediate restabilization of newly formed synapses, which is also associated with increased AMPA trafficking and insertion (Rumpel et al., 2005; Yu et al., 2008; Migues et al., 2010; Nedelescu et al., 2010). $\boldsymbol{b}$, In the presence of Dkk-1, restabilization does not occur, preventing normal memory consolidation. c, In the presence of Wnt1, the initial labile phase is prevented, also preventing normal memory consolidation. dendritic branching ( $\mathrm{Yu}$ and Malenka, 2003). Our results show that overexpression of Dkk-1 in vivo prevents memory formation. We found that infusing Dkk-1 into the amygdala before fear conditioning does not affect the acquisition or immediate expression of fear, but does produce deficits in learning when measured $48 \mathrm{~h}$ after training. The observed behavioral effect does not appear to be a result of neurotoxicity or alterations in baseline anxiety or locomotor activity. Notably, as found in Table 1, we find that endogenous Dkk-1 is transiently increased during fear consolidation. This is consistent with a transient decrease in Wnt signaling playing a role in plasticity and memory formation. We think that disrupting the normal temporal control of Wnt inhibition, as well as the likely more profound effect of exogenous Dkk-1 beyond endogenous levels, led to abnormal Wnt regulation. Thus, the Dkk-1 behavioral results suggest that dynamic regulation of Wnt signaling is required for the consolidation of new memory.

We chose Dkk-1 for our studies since it is a well known, and commonly used, inhibitor of the Wnt pathway, both in vitro and in vivo (Grotewold and Rüther, 2002; Shou et al., 2002; Wirths et al., 2003; Verani et al., 2007; Matrisciano et al., 2011). One potential limitation of this work is the lack of small molecule pharmacological antagonists targeting the Wnt pathway. Future studies using a genetic silencer of Wnt signaling would be important to both target specific cell populations and more precisely target amygdala subregions.

To further examine its role in memory formation, in vivo, we infused Wnt 1 into the amygdala either before or after fear conditioning. We found that infusing Wnt1 in the amygdala before training did not affect acquisition, but resulted in deficits in the expression of fear as measured $48 \mathrm{~h}$ after training. The infusion of Wnt1 after training did not have an effect on learning. Given that acquisition of fear appeared to be normal in the presence of Wnt1, these data suggest that we may be preventing the normal rapid decrease in Wnt signaling that occurs in training and/or immediately after training during the early period of consolidation. These data suggest that an immediate decrease in Wnt1 with learning may be required for memory formation; thus, the infusion of Wntl before training, may allow just enough time to reverse that downregulation of Wntl gene expression. Conversely, infusing Wntl after training, may not increase expression of Wnt1 until after a critical period of early consolidation has passed. Therefore, our results suggest that inhibiting the decrease in Wnt 1 expression that occurs with training produces memory deficits.

Interestingly, the observed downregulation of endogenous Wnt 1 immediately following training closely resembles the alterations seen in the interaction of $\beta$-catenin with cadherin following fear conditioning (Maguschak and Ressler, 2008). There has been much discussion regarding the crosstalk between Wnt signaling and cell adhesion. Previous in vitro work in non-neuronal cells has shown that Wnt stimulation leads to an increase in cellcell adhesion (Hinck et al., 1994; Medrek et al., 2009). Furthermore, there are many lines of convergent data suggesting that 
Wnts may both directly and indirectly regulate $\beta$-catenin interactions with cadherin (Nelson and Nusse, 2004). Our results showed that Wnt1 may have a similar effect in promoting $\beta$-catenin/cadherin stability in vivo within the adult brain, and conversely that Wnt inhibition or downregulation may destabilize these complexes. We found that infusing Wnt1 into the amygdala before training prevented the destabilization of the $\beta$-catenin/cadherin interaction that occurs immediately following fear conditioning. This lack of transient destabilization may prevent synaptic modifications from taking place that are required for new memory formation.

Of note, most of our dynamic Wnt expression appears to be localized to the basal amygdala (Fig. 2), and our Dkk-1 and Wnt1 infusions targeted basal as much as lateral subdivisions. However, the majority of work on auditory fear conditioning in rats suggests that the basal nucleus is not required for auditory fear conditioning (Amorapanth et al., 2000; Nader et al., 2001). We have several thoughts related to this: (1) as far as we are aware, most of the auditory fear conditioning pointing exclusively to the lateral amygdala studies have been performed in rats, not mice, which are used in these studies; (2) the lateral amygdala actually extends quite ventrally at the more rostral regions of the brain where these in situ hybridizations were performed, making it difficult to separate ventrolateral subdivisions from basolateral; (3) we have performed other mouse genetic and pharmacological manipulations targeting the basolateral region, finding robust effects on tone fear conditioning in mice (e.g., Heldt and Ressler, 2007; Maguschak and Ressler, 2008); and (4) at least some work has been done suggesting that lesions of the anterior division of the basal nuclei in rats disrupt auditory fear conditioning (Goosens and Maren, 2001).

We have previously shown that $\beta$-catenin in the amygdala is required for the normal consolidation of fear memory, and that the interaction between $\beta$-catenin and cadherin is altered during this process (Maguschak and Ressler, 2008). Those data suggest that $\beta$-catenin/cadherin complexes are involved in normal synaptic stability, and that transient disruption of stable synapses may be required for new synapse formation to occur. Here, we show that Wnt signaling may contribute to $\beta$-catenin's effect on learning and memory. As schematized in Figure 7, we propose that during the acquisition of fear memory and immediately after, normal Wnt signaling is significantly reduced, which may allow for phosphorylation of the Y654 site on $\beta$-catenin, contributing to $\beta$-catenin/cadherin destabilization (Murase et al., 2002), and subsequent synaptic weakening (Arikkath and Reichardt, 2008). Then, once the synapses have been modified during the consolidation process, Wnt signaling is normalized, the $\beta$-catenin Y654 site is dephosphorylated, and $\beta$-catenin/cadherin interaction is subsequently restored, stabilizing the new synapses (Bamji et al., 2006). These processes of Wnt-dependent $\beta$-catenin/cadherin-mediated synapse stability, coupled with transient destabilization and restabilization during memory consolidation, may provide for a structural mechanism underlying long-term memory formation and stability.

\section{References}

Ahmad-Annuar A, Ciani L, Simeonidis I, Herreros J, Fredj NB, Rosso SB, Hall A, Brickley S, Salinas PC (2006) Signaling across the synapse: a role for Wnt and Dishevelled in presynaptic assembly and neurotransmitter release. J Cell Biol 174:127-139.

Amorapanth P, LeDoux JE, Nader K (2000) Differential lateral amygdala outputs mediate reactions and actions elicited by a fear-arousing stimulus. Nat Neurosci 3:74-79.
Arikkath J, Reichardt LF (2008) Cadherins and catenins at synapses: roles in synaptogenesis and synaptic plasticity. Trends Neurosci 31:487-494.

Bamji SX, Rico B, Kimes N, Reichardt LF (2006) BDNF mobilizes synaptic vesicles and enhances synapse formation by disrupting cadherin-betacatenin interactions. J Cell Biol 174:289-299.

Bhanot P, Brink M, Samos CH, Hsieh JC, Wang Y, Macke JP, Andrew D, Nathans J, Nusse R (1996) A new member of the frizzled family from Drosophila functions as a Wingless receptor. Nature 382:225-230.

Caricasole A, Copani A, Caraci F, Aronica E, Rozemuller AJ, Caruso A, Storto M, Gaviraghi G, Terstappen GC, Nicoletti F (2004) Induction of Dickkopf-1, a negative modulator of the Wnt pathway, is associated with neuronal degeneration in Alzheimer's brain. J Neurosci 24:6021-6027.

Chen J, Park CS, Tang SJ (2006) Activity-dependent synaptic Wnt release regulates hippocampal long term potentiation. J Biol Chem 281:1191011916.

De Ferrari GV, Inestrosa NC (2000) Wnt signaling function in Alzheimer's disease. Brain Res Brain Res Rev 33:1-12.

De Ferrari GV, Moon RT (2006) The ups and downs of Wnt signaling in prevalent neurological disorders. Oncogene 25:7545-7553.

Diep DB, Hoen N, Backman M, Machon O, Krauss S (2004) Characterisation of the Wnt antagonists and their response to conditionally activated Wnt signalling in the developing mouse forebrain. Brain Res Dev Brain Res 153:261-270.

Goosens KA, Maren S (2001) Contextual and auditory fear conditioning are mediated by the lateral, basal, and central amygdaloid nuclei in rats. Learn Mem 8:148-155.

Gordon MD, Nusse R (2006) Wnt signaling: multiple pathways, multiple receptors, and multiple transcription factors. J Biol Chem 281:2242922433.

Grotewold L, Rüther U (2002) The Wnt antagonist Dickkopf-1 is regulated by Bmp signaling and c-Jun and modulates programmed cell death. EMBO J 21:966-975.

Hall AC, Lucas FR, Salinas PC (2000) Axonal remodeling and synaptic differentiation in the cerebellum is regulated by WNT-7a signaling. Cell 100:525-535.

Heldt SA, Ressler KJ (2007) Training-induced changes in the expression of GABAA-associated genes in the amygdala after the acquisition and extinction of Pavlovian fear. Eur J Neurosci 26:3631-3644.

Hinck L, Nelson WJ, Papkoff J (1994) Wnt-1 modulates cell-cell adhesion in mammalian cells by stabilizing beta-catenin binding to the cell adhesion protein cadherin. J Cell Biol 124:729-741.

Keeley MB, Wood MA, Isiegas C, Stein J, Hellman K, Hannenhalli S, Abel T (2006) Differential transcriptional response to nonassociative and associative components of classical fear conditioning in the amygdala and hippocampus. Learn Mem 13:135-142.

Krylova O, Herreros J, Cleverley KE, Ehler E, Henriquez JP, Hughes SM, Salinas PC (2002) WNT-3, expressed by motoneurons, regulates terminal arborization of neurotrophin-3-responsive spinal sensory neurons. Neuron 35:1043-1056.

Kuang HB, Miao CL, Guo WX, Peng S, Cao YJ, Duan EK (2009) Dickkopf-1 enhances migration of HEK293 cell by beta-catenin/E-cadherin degradation. Front Biosci 14:2212-2220.

Lee SH, Peng IF, Ng YG, Yanagisawa M, Bamji SX, Elia LP, Balsamo J, Lilien J, Anastasiadis PZ, Ullian EM, Reichardt LF (2008) Synapses are regulated by the cytoplasmic tyrosine kinase Fer in a pathway mediated by p120catenin, Fer, SHP-2, and beta-catenin. J Cell Biol 183:893-908.

Livak KJ, Schmittgen TD (2001) Analysis of relative gene expression data using real-time quantitative PCR and the 2(-Delta Delta $\mathrm{C}(\mathrm{T})$ ) method. Methods 25:402-408.

Logan CY, Nusse R (2004) The Wnt signaling pathway in development and disease. Annu Rev Cell Dev Biol 20:781-810.

Lucas FR, Salinas PC (1997) WNT-7a induces axonal remodeling and increases synapsin I levels in cerebellar neurons. Dev Biol 192:31-44.

Maguschak KA, Ressler KJ (2008) Beta-catenin is required for memory consolidation. Nat Neurosci 11:1319-1326.

Matrisciano F, Busceti CL, Bucci D, Orlando R, Caruso A, Molinaro G, Cappuccio I, Riozzi B, Gradini R, Motolese M, Caraci F, Copani A, Scaccianoce S, Melchiorri D, Bruno V, Battaglia G, Nicoletti F (2011) Induction of the Wnt antagonist Dickkopf-1 is involved in stress-induced hippocampal damage. PLoS One 6:e16447.

Medrek C, Landberg G, Andersson T, Leandersson K (2009) Wnt-5aCKI $\{$ alpha $\}$ signaling promotes $\{$ beta $\}$-catenin/E-cadherin complex for- 
mation and intercellular adhesion in human breast epithelial cells. J Biol Chem 284:10968-10979.

Mei B, Li C, Dong S, Jiang CH, Wang H, Hu Y (2005) Distinct gene expression profiles in hippocampus and amygdala after fear conditioning. Brain Res Bull 67:1-12.

Migues PV, Hardt O, Wu DC, Gamache K, Sacktor TC, Wang YT, Nader K (2010) PKMzeta maintains memories by regulating GluR2-dependent AMPA receptor trafficking. Nat Neurosci 13:630-634.

Moon RT, Kohn AD, De Ferrari GV, Kaykas A (2004) WNT and betacatenin signalling: diseases and therapies. Nat Rev Genet 5:691-701.

Murase S, Mosser E, Schuman EM (2002) Depolarization drives betaCatenin into neuronal spines promoting changes in synaptic structure and function. Neuron 35:91-105.

Nader K, Majidishad P, Amorapanth P, LeDoux JE (2001) Damage to the lateral and central, but not other, amygdaloid nucleu prevents the acquisition of auditory fear conditioning. Learn Mem 8:156-163.

Nedelescu H, Kelso CM, Lázaro-Muñoz G, Purpura M, Cain CK, Ledoux JE, Aoki C (2010) Endogenous GluR1-containing AMPA receptors translocate to asymmetric synapses in the lateral amygdala during the early phase of fear memory formation: an electron microscopic immunocytochemical study. J Comp Neurol 518:4723-4739.

Nelson WJ, Nusse R (2004) Convergence of Wnt, beta-catenin, and cadherin pathways. Science 303:1483-1487.

Paxinos G, Franklin KBJ (2004) The mouse brain in stereotaxic coordinates, Ed 2. San Diego: Academic.

Ressler KJ, Paschall G, Zhou XL, Davis M (2002) Regulation of synaptic plasticity genes during consolidation of fear conditioning. J Neurosci 22:7892-7902.
Rumpel S, LeDoux J, Zador A, Malinow R (2005) Postsynaptic receptor trafficking underlying a form of associative learning. Science 308:83-88.

Shou J, Ali-Osman F, Multani AS, Pathak S, Fedi P, Srivenugopal KS (2002) Human Dkk-1, a gene encoding a Wnt antagonist, responds to DNA damage and its overexpression sensitizes brain tumor cells to apoptosis following alkylation damage of DNA. Oncogene 21:878-889.

Stork O, Stork S, Pape HC, Obata K (2001) Identification of genes expressed in the amygdala during the formation of fear memory. Learn Mem 8:209-219.

Verani R, Cappuccio I, Spinsanti P, Gradini R, Caruso A, Magnotti MC, Motolese M, Nicoletti F, Melchiorri D (2007) Expression of the Wnt inhibitor Dickkopf-1 is required for the induction of neural markers in mouse embryonic stem cells differentiating in response to retinoic acid. J Neurochem 100:242-250.

Wayman GA, Impey S, Marks D, Saneyoshi T, Grant WF, Derkach V, Soderling TR (2006) Activity-dependent dendritic arborization mediated by CaM-kinase I activation and enhanced CREB-dependent transcription of Wnt-2. Neuron 50:897-909.

Wirths O, Waha A, Weggen S, Schirmacher P, Kühne T, Goodyer CG, Albrecht S, Von Schweinitz D, Pietsch T (2003) Overexpression of human Dickkopf-1, an antagonist of wingless/WNT signaling, in human hepatoblastomas and Wilms' tumors. Lab Invest 83:429-434.

Yu SY, Wu DC, Liu L, Ge Y, Wang YT (2008) Role of AMPA receptor trafficking in NMDA receptor-dependent synaptic plasticity in the rat lateral amygdala. J Neurochem 106:889-899.

Yu X, Malenka RC (2003) Beta-catenin is critical for dendritic morphogenesis. Nat Neurosci 6:1169-1177. 